\title{
Risk of malignancy index 4 in preoperative evaluation of patients with ovarian tumours
}

\author{
Sunita Singhal, Lata Rajoria, Premlata Mital*, Alka Batar, Richa Ainani, \\ Monika Agarwal, Urmila, Kavita Chaudhary
}

Department of Obstetrics and Gynecology, S.M.S. Medical College, Jaipur, Rajasthan, India

Received: 14 April 2018

Accepted: 08 May 2018

\section{*Correspondence:}

Dr. Premlata Mital,

E-mail: drpremlatamital@rediffmail.com

Copyright: ( $)$ the author(s), publisher and licensee Medip Academy. This is an open-access article distributed under the terms of the Creative Commons Attribution Non-Commercial License, which permits unrestricted non-commercial use, distribution, and reproduction in any medium, provided the original work is properly cited.

\begin{abstract}
Background: Ovarian tumors usually presents as adnexal masses which may be benign or malignant. Accurate and timely diagnosis of an adnexal mass is a challenge for the gynecologists. Currently clinical examination, ultrasonographic assessment and ovarian tumour markers (CA 125, beta hCG, AFP, LDH) are routinely done at our centre to evaluate patients with ovarian tumours. The study was designed to evaluate the ability of RMI 4 to discriminate benign ovarian tumor from malignant ovarian tumor in patients attending Department of Obstetrics and Gynaecology, S.M.S. Medical College, Jaipur.

Methods: 200 patients diagnosed to have ovarian tumours were included in the study after obtaining written consent. Ultrasonographic characteristic, menopausal status and serum CA 125 levels were documented preoperatively. Risk of malignancy index 4 was calculated and correlated with histopathological diagnosis.

Results: At a cut-off point of 450, RMI 4 had a sensitivity of $67.5 \%$ (95\% CI: $50.87-81.43 \%$ ), specificity of $98.75 \%$ (95.56-99.85\%), positive likelyhood ratio of 54, negative likelyhood ratio of 0.33 , a positive predictive value of $93.1 \%$, negative predictive value of $92.4 \%$ and diagnostic accuracy of $92.5 \%$.

Conclusions: RMI 4 is a simple, cost effective, reliable scoring system that is easily applicable method in primary evaluation of patients with ovarian tumours with a sensitivity of $67.5 \%$ and specificity of $98.75 \%$.
\end{abstract}

Keywords: CA 125, Malignancy, Ovarian tumour, Risk of malignancy index, Ultrasonography

\section{INTRODUCTION}

Ovarian malignancy is third most common cancer in females after cervical and breast carcinoma and unfortunately it remains clinically silent until advance stage of disease leading to higher mortality rate. ${ }^{1,2} \mathrm{Up}$ to $60 \%$ ovarian tumours in postmenopausal women are malignant as compared to $24 \%$ ovarian tumours in premenopausal women. ${ }^{3-5}$

Ovarian tumors usually presents as adnexal masses which may be benign or malignant. Accurate and timely diagnosis of an adnexal mass is a challenge for the gynecologists, because the type of surgical procedure and the experience of the surgeon are important for the prognosis of ovarian carcinoma. Apart from clinical evaluation, ultrasonography, tumour markers and radiological investigations have been proposed to evaluate ovarian tumours. Unfortunately, none of these methods has shown significantly better performance in discriminating malignant tumors from benign tumours. Risk of malignancy index is a mathematical formula which incorporates menopausal status, serum level of CA125 and ultrasonographic score. RMI was first developed by Jacob et al, in 1990 to discriminate between malignant and benign ovarian tumours. ${ }^{6}$ Using an RMI cut-off level of 200 , they observed sensitivity to be $85 \%$ 
and the specificity $97 \%$. Patients with an RMI score of greater than $200 \mathrm{had}$, on average, 42 times the background risk of cancer and those with a lower value 0.15 times the background risk. Tingulstand et al, in1996 developed RMI 2 and in 1999 developed RMI 3 to discriminate between malignant and benign pelvic masses. $^{7,8}$ In 2009 Yamamoto et al, developed RMI 4 by adding tumour size in previous criteria and found that the accuracy of the RMI 4 with a cut off level $>450$ was better than RMI $1(\mathrm{P}=0.0013)$, RMI $2(\mathrm{P}=0.0009)$ and RMI 3 (P=0.0013). ${ }^{9}$

Currently clinical examination, ultrasonographic assessment and ovarian tumour markers (CA 125, beta hCG, AFP, LDH) are routinely done at our centre to evaluate patients with ovarian tumours. The study was designed to evaluate the ability of RMI 4 to discriminate benign ovarian tumor from malignant ovarian tumor in patients attending Department of Obstetrics and Gynaecology, S.M.S. Medical College, Jaipur.

\section{METHODS}

200 patients diagnosed to have ovarian tumours were included in the study. All patients were informed about the nature of the study and a written informed consent was obtained prior to enrollment in the study. Clearance from ethical committee was also taken. Patients who had advanced ovarian malignancies, secondary ovarian malignancies, history of unilateral oophorectomy were excluded from the study. A detailed history was obtained from all patients. A complete general physical, systemic and gynecological examination was performed. All patients were evaluated by transabdominal or transvaginal ultrasound by ultrasound machine Prosound ALOKA ALFA 6 using abdominal $(3.75 \mathrm{MHz})$ and vaginal probes $(7.5 \mathrm{MHz})$. On ultrasonographic examination, findings of ovary particularly multilocularity, solidity, bilaterality, ascites and presence of metastasis were noted. 1 point was given to each criteria. USG score was assigned as $U=1$ if 0 or 1 criteria fulfilled and $\mathrm{U}=4$ if 2 or more criteria are fulfilled.

Size of ovarian tumour was also measured. Score 1was given for tumour less than $7 \mathrm{~cm}$ and score 2 for tumour more than $7 \mathrm{~cm}$ in size.

For estimation of serum CA 125 levels, $5 \mathrm{ml}$ of venous blood was collected and assayed by MEIA (micro particle enzyme immunoassay) technique for quantitative measurement. The optimal cut off value of serum CA 125 was $35 \mathrm{U} / \mathrm{ml}$.

Postmenopausal status is defined as amenorrhea of more than one year or age older than 50 years in women who had a hysterectomy. Women who did not meet these criteria were classified as premenopausal. Menopausal score was assigned as $\mathrm{M}=1$ for premenopausal and $\mathrm{M}=4$ if postmenopausal.
Risk of malignancy index 4 was calculated as a product of $U \times M \times S$ (size in centimeters) $\times \mathrm{S}$. CA-125. A cutoff value of 450 was used to differentiate between benign and malignant ovarian tumours.

All women underwent laparotomy/staging laparotomy after PAC clearance. Surgically removed specimens were sent for histopathological examination. Risk of malignancy index 4 was correlated with histopathological diagnosis considered as gold standard.

Statistical analysis was done by standard statistical methods and a $\mathrm{p}$ value $<0.05$ was considered significant. Performance of RMI 4 was analyzed in the form of sensitivity, specificity, positive predictive value, negative predictive value and diagnostic ability.

\section{RESULTS}

Out of 200 patients, 160 patients $(80 \%)$ had benign and $40(20 \%)$ had malignant ovarian tumour. Disease prevalence in our study was $20 \%$. The distribution of patients by age, menopausal status, ultrasound score, tumour size score and serum Ca-125 level is shown in Table 1 .

Table 1: Distribution of patients by age, menopausal status, serum CA125 levels, ultrasound score and tumour size score.

\begin{tabular}{|c|c|c|c|c|c|}
\hline \multirow[t]{2}{*}{ Variables } & \multicolumn{2}{|c|}{$\begin{array}{l}\text { Benign } \\
(n=160)\end{array}$} & \multicolumn{2}{|c|}{$\begin{array}{l}\text { Malignant } \\
(n=40)\end{array}$} & \multirow[t]{2}{*}{ p value } \\
\hline & No. & $\%$ & No. & $\%$ & \\
\hline \multicolumn{6}{|l|}{ Age (years) } \\
\hline$<30$ & 88 & 55 & 8 & 20 & \multirow{2}{*}{$\begin{array}{l}0.00007 \\
\text { significant }\end{array}$} \\
\hline$>30$ & 72 & 45 & 32 & 80 & \\
\hline \multicolumn{6}{|c|}{ Menopausal status } \\
\hline Premenopausal & 135 & 84.4 & 24 & 60 & \multirow{2}{*}{$\begin{array}{l}0.0006 \\
\text { significant }\end{array}$} \\
\hline Postmenopausal & 25 & 15.6 & 16 & 40 & \\
\hline \multicolumn{6}{|l|}{ USG Score } \\
\hline 1 & 151 & 94.4 & 8 & 20 & \multirow{2}{*}{$\begin{array}{l}0.0000 \\
\text { significant }\end{array}$} \\
\hline 4 & 9 & 5.6 & 32 & 80 & \\
\hline \multicolumn{6}{|c|}{ Serum CA 125(U/ml) } \\
\hline$<35$ & 144 & 90 & 10 & 25 & \multirow{2}{*}{$\begin{array}{l}0.000 \\
\text { significant }\end{array}$} \\
\hline$>35$ & 16 & 10 & 30 & 75 & \\
\hline \multicolumn{6}{|c|}{ Tumour Size score } \\
\hline 1 & 83 & 51.9 & 12 & 30 & \multirow{2}{*}{$\begin{array}{l}0.01 \\
\text { significant }\end{array}$} \\
\hline 2 & 77 & 48.1 & 28 & 70 & \\
\hline
\end{tabular}

$80 \%$ patients with malignant tumours were above 30 years of age in contrast to $45 \%$ patients with benign tumours. The association of patient's age with disease status was statistically significant (p 0.00007). $40 \%$ patients with malignant ovarian tumours were postmenopausal as compared to $15.6 \%$ patients with benign ovarian tumour and the difference was statistically significant ( $p$.0006). The association between ultrasound score and disease status and tumour size score and disease status was statistically significant at a $p$ value of 
0.0000 and .01 respectively. $75 \%$ patients with malignant ovarian tumours had a CA 125 level $>35 \mathrm{U} / \mathrm{ml}$ as compare to $10 \%$ patients with benign tumours. The difference in the level of CA 125 in benign and malignant ovarian tumours was statistically significant ( $\mathrm{p}-0.000)$.

Performance of RMI 4 is shown in Table 2. Out of 29 patients having RMI 4 of $>450,27(93.1 \%)$ had malignant tumour and $6.9 \%$ had benign tumour. 171 patients had RMI 4 score <450, of which $158(92.4 \%)$ had benign tumour and 7.65 had malignant tumour. 40 patient had malignant ovarian tumours on histopathological examination, out of which 27 were malignant by RMI 4 (True positive). 160 ovarian tumours were benign on histopathological examination, out of which 158 were benign by RMI 4 (True negative). At a cut-off point of 450 , RMI 4 had a sensitivity of $67.5 \%$ (95\% CI: $50.87-81.43 \%$ ), specificity of $98.75 \%$ (95.56$99.85 \%$ ), positive likelyhood ratio of 54 , negative likelyhood ratio of 0.33 , a positive predictive value of $93.1 \%$, negative predictive value of $92.4 \%$ and diagnostic accuracy of $92.5 \%$ (Table 3 ).

Table 2: Analysis of performance of risk of malignant index 4.

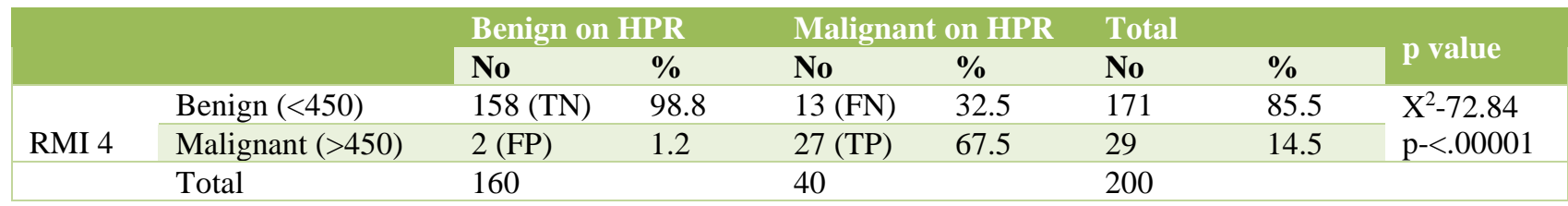

Table 3: Evaluation of RMI 4.

\begin{tabular}{|llll}
\hline Statistic & Formula & Value & $95 \%$ CI \\
\hline Disease Prevalence & TP+FN/TP+FP+FP+TN & $20 \%$ & $14.69-26.22 \%$ \\
\hline Sensitivity & TP/TP+FN & $67.5 \%$ & $50.87-81.43 \%$ \\
\hline Specificity & TN/TN+FP & $98.75 \%$ & $95.56-99.85 \%$ \\
\hline Positive likelihood Ratio & Sensitivity/1-Specificity & 54.0 & $13.40-217.65$ \\
\hline Negative likelihood Ratio & 1-Sensitivity/Specificity & 0.33 & $0.21-0.51$ \\
\hline PPV & TP/TP+FP & $93.1 \%$ & $77.01-98.2 \%$ \\
\hline NPV & TN/FN+TN & $92.4 \%$ & $88.6-95 \%$ \\
Accuracy & TP+TN/TP+FP+FN+TN & $92.5 \%$ & $87.93-95.74 \%$ \\
\hline
\end{tabular}

Table 4: Performance of RMI 4, menopausal status, USG score, tumour size score and serum CA 125 levels.

\begin{tabular}{|c|c|c|c|c|c|}
\hline Variables & RMI & Menopausal status & USG score & Tumour size score & S. CA 125 \\
\hline $\begin{array}{l}\text { Sensitivity } \\
(95 \% \text { CI })\end{array}$ & $67.5(50.87-81.43)$ & $40(24.86-56.67)$ & $80(64.35-90.95)$ & $70(53.4-83.44)$ & $75(58.80-87.31)$ \\
\hline $\begin{array}{l}\text { Specificity } \\
(95 \% \text { CI })\end{array}$ & $98.7(95.56-99.85)$ & 84.3 (77.80- 89.63) & $94.38(89.59-97.40)$ & $51.88(43.85-59.83)$ & $90(84.27-94.18)$ \\
\hline $\begin{array}{l}\text { Positive } \\
\text { likelihood ratio } \\
(95 \% \mathrm{CI})\end{array}$ & $54.0(13.40-217.65)$ & $2.56(1.52$ to 4.32$)$ & $14.22(7.40-27.33)$ & $1.45(1.12-1.88)$ & $7.50(4.56-12.34)$ \\
\hline $\begin{array}{l}\text { Negative } \\
\text { likelihood Ratio } \\
(95 \% \text { CI) }\end{array}$ & $0.33(0.21-0.51)$ & $0.71(0.55$ to 0.92$)$ & $0.21(0.11-0.39)$ & $0.58(0.35-0.95)$ & $0.28(0.16-0.48)$ \\
\hline PPV (95\% CI) & $93.1(77.01-98.2)$ & $39.02(27.50-51.92)$ & $78.05(64.91-87.23)$ & $26.67(21.92-32.02)$ & $65.2(53.26-75.52)$ \\
\hline NPV $(95 \%$ CI) & $92.4(88.6-95)$ & $84.91(81.24-87.96)$ & $94.97(91.03-97.23)$ & $87.37(80.81-91.91)$ & $93.5(89.36-96.11)$ \\
\hline $\begin{array}{l}\text { Diagnostic } \\
\text { accuracy } \\
(95 \% \mathrm{CI})\end{array}$ & $92.5(87.93-95.74)$ & $75.5(68.94-81.29)$ & $91.5(86.74-94.97)$ & $55.5(48.32-62.51)$ & $87(81.53-91.33)$ \\
\hline
\end{tabular}

Table 4 compares performance of RMI with menopausal status, USG score, tumour size score and S CA 125 level used individually to discriminate benign and malignant ovarian tumours. RMI at a cutoff point of 450 had a sensitivity of $67.5 \%$, specificity of $98.75 \%$, positive likelihood ratio of 54 , negative likelyhood ratio of 0.33 , a positive predictive value of $93.1 \%$, negative predictive value of $92.4 \%$ and diagnostic accuracy of $92.5 \%$. Menopausal status had a sensitivity of $40 \%$, specificity of $84.3 \%$, positive likelihood ratio of 2.56 , negative likelyhood ratio of 0.71 , a positive predictive value of $39.02 \%$, negative predictive value of $84.91 \%$ and 
diagnostic accuracy of $75.5 \%$. Ultra sound score had a sensitivity of $80 \%$, specificity of $94.38 \%$, positive likelihood ratio of 14.22 , negative likelyhood ratio of 0.21 , a positive predictive value of $78.05 \%$, negative predictive value of $94.97 \%$ and diagnostic accuracy of $91.5 \%$. Tumour size score had a sensitivity of $70 \%$, specificity of $51.88 \%$, positive likelihood ratio of 1.45 , negative likelyhood ratio of 0.58 , a positive predictive value of $26.67 \%$, negative predictive value of $87.37 \%$ and diagnostic accuracy of $55.5 \%$. Serum CA 125 level had a sensitivity of $75 \%$, specificity of $90 \%$, positive likelihood ratio of 7.5 , negative likelyhood ratio of 0.28 , a positive predictive value of $65.2 \%$, negative predictive value of $93.5 \%$ and diagnostic accuracy of $87 \%$ (Table 4).

\section{DISCUSSION}

The present study was done to evaluate RMI 4 in discriminating benign from malignant ovarian tumours. 200 patients with ovarian tumours were recruited out of them $40(20 \%)$ patients were diagnosed to have malignant tumours.

Occurrence of malignant ovarian tumours was lower $(20 \%)$ in our study than that $(35 \%)$ observed by $\mathrm{G} \mathrm{O}$ Abdulrahman $\mathrm{Jr}$ et al, in their study and higher than that (15\%) observed by Abdel Baset F. Mohammed et al. ${ }^{10,11}$

Mean age of patients with benign tumour $(33.93 \pm 13.67$ yrs) was lower than that for malignant ovarian tumour (44.07 $\pm 14.17 \mathrm{yrs})$. Our results were consistent with that observed by Ashrafgangooei T et al, Dora et al 2017. ${ }^{2,13}$ The association of patient's age with disease status was statistically significant (p 0.00007).

There was highly significant difference among benign and malignant ovarian tumours regarding menopausal status of the patients ( $\mathrm{p}-0.0006$ ) with $40 \%$ women with malignant tumours were post-menopausal as compared to $15.6 \%$ women with benign tumours. Our results were similar to that observed by Radhamani and Akhila, who in their study observed that majority of the tumours belonged to postmenopausal group, Dora et al who observed that among the postmenopausal patients, $81.6 \%$ had malignant disease as compared to premenopausal women and Arun-Muthuvel V who observed that $61 \%$ of the ovarian tumours in postmenopausal women were malignant. ${ }^{13-15}$

High false positive rates was observed for ultrasound $(5.6 \%)$, tumour size score $(48.1 \%)$ and CA 125 levels $(10 \%)$ when used individually as compared to low false positive rate $(1.2 \%)$ observed with RMI 4 . In our study, at a cut-off point of 450, RMI 4 had a sensitivity as $67.5 \%$, specificity as $98.75 \%$, PPV as $93.1 \%$, NPV as $92.4 \%$ and diagnostic accuracy of $92.5 \%$. Our results were comparable with various studies done in the past. Yamamoto et al, developed RMI 4 by using tumor size along with other parameters. ${ }^{9}$ They observed that at a cut- off level of 450 the sensitivity, specificity, positive predictive value, negative predictive value and accuracy were respectively, $86.8 \%, 91.0 \%, 63.5 \%, 97.5 \%$, and $90.4 \%$. Aktürk E et al, in their study reported that RMI 4 has a sensitivity, specificity, PPV, NPV and diagnostic accuracy as $84 \%, 87 \%, 60 \%, 95 \%$ and $86 \%$ respectively. ${ }^{16}$ Jung-Woo Park et al, observed that for RMI 4, sensitivity, specificity, PPV, NPV and diagnostic accuracy was $75.2 \%, 87.5 \%, 61.2 \%, 93.1 \%$ and $85 \%$ respectively. ${ }^{17}$

Mohammed ABF et al, in their study stated that RMI 4 has a sensitivity, specificity. ${ }^{11} \mathrm{PPV}, \mathrm{NPV}$ and diagnostic accuracy as $76.9 \%, 93.8 \%, 71.4 \%, 95.3 \%$ and $91 \%$ respectively.

The prevalence of ovarian neoplasm has been rising during last decades. Silent occurrence, slow progression, makes its mortality rate the highest among gynecological malignancies. There is no universal screening method for discriminating between benign and malignant ovarian tumours yet. So many authors have tried for earliest diagnosis of malignant ovarian tumours by various parameters. These may be earliest clinical features, tumour markers, imaging studies, cytology but no one yet is a definite method for screening of cancer ovary. The present study demonstrated that in the absence of a definite biomarker, the multi parametric risk of malignancy index, RMI 4 is better tool in discriminating benign and malignant tumours. The sensitivity of RMI 4 was $67.5 \%$ and specificity of $98.75 \%$.

\section{CONCLUSION}

In conclusion, the RMI 4 is a simple, cost effective, reliable scoring system that is easily applicable method in primary evaluation of patients with ovarian tumours in daily clinical practice by all gynecologists. Use of RMI 4 in discriminating between benign and malignant ovarian tumour will help in timely referral of patient to specialized oncologist/gynecologists for effective surgical intervention/ management.

\section{Funding: No funding sources}

Conflict of interest: None declared

Ethical approval: The study was approved by the Institutional Ethics Committee

\section{REFERENCES}

1. Hartenbach EM, Remington PL. Trends in united states ovarian mortality. 1979-1995.Obstet Gynecol. 1999;93:30-3.

2. Prasad AE, Nandennava M, Ganesh MS, Karpurmath SV, Hatti J. Demographic and clinicopathologic profile of malignant epithelial ovarian tumors: an experience from a tertiary cancer care centre in Bangalore, South India. Int J Reprod Contracept Obstet Gynecol 2017;6:856-60. 
3. Gillis CR, Hole DJ, Still RM, Davis J, Kaye SB. Medical audit, cancer registration, and survival in ovarian cancer. Lancet. 1991;337:611-2.

4. Finkler NJ, Benacerraf B, Lavin PT, Wojciechowski C, Knapp RC. Comparison of serum CA-125, clinical impression, and ultrasound in the preoperative evaluation of ovarian masses. Obstet Gynecol. 1988;72:659-64.

5. Vasilev SA, Schlaerth JB, Campeau J, Morrow CP. Serum CA-125 levels in preoperative evaluation of pelvic masses. Obstet Gynecol. 1988;71:751-6.

6. Jacob I, Oram D, Fairbanks J, Turner J, Frost C. A risk of malignancy index incorporating CA 125, ultrasound and menopausal status for the accurate pre operative diagnosis of ovarian Cancer. $\mathrm{Br} \mathrm{J}$ Obstet Gynaecol. 1990;97:922-9.

7. Tingulstand S, Hagen B, Onsrud M, Kiserud $\mathrm{T}$. Evaluation of Risk of Malignancy Index based on. serum CA125, Ultrasound findings and menopausal status in the preoperative diagnosis of pelvic masses. Br J Obstet Gynecol. 1996;103:826-31.

8. Tingulstad S, Hagen B, Skjeldestad FE, Halvorsen T, Nustad K, Onsrud M. The risk-of-malignancy index to evaluate potential ovarian cancers in local hospitals. Obstetrics Gynecology. 1999 Mar 1;93(3):448-52.

9. Yamamoto Y, Yamada R, Oguri H, Maeda N, Fukaya T. Comparison of four malignancy risk indices in the preoperative evaluation of patients with pelvic masses. Euro J Obst Gynecol Reprod Biol. 2009 Jun 1;144(2):163-7.

10. Abdulrahman GO, McKnight L, Singh KL. The risk of malignancy index (RMI) in women with adnexal masses in Wales. Taiwanese J Obst Gynecol. 2014 Sep 1;53(3):376-81.

11. Mohammed AB, Ahuga VK, Taha M. Validation of the Risk of Malignancy Index in primary evaluation of ovarian masses. Middle East Fertility Society J. 2014 Dec 1;19(4):324-8.

12. Ashrafgangooei T, Rezaeezadeh M. Risk of malignancy index in preoperative evaluation of pelvic masses. Asian Pac J Cancer Prev. 2011 Jan 1;12(07):1727-30.

13. Dora SK, Dandapat AB, Pande B, Hota JP. A prospective study to evaluate the risk malignancy index and its diagnostic implication in patients with suspected ovarian mass. J ovarian research. 2017 Dec;10(1):55.

14. Radhamani S, Akhila MV. Evaluation of adnexal masses-correlation of clinical, sonological and histopathological findings in adnexal masses. Inter $\mathbf{J}$ Scientific Study. 2017;4(11):88-92.

15. Arun-Muthuvel V, Jaya V. Pre-operative evaluation of ovarian tumors by risk of malignancy index, CA125 and ultrasound. Asian Pac J Cancer Prev. 2014 Jan 1;15(6):2929e32.

16. Aktürk E, Karaca RE, Alanbay İ, Dede M, Karaşahin $\mathrm{E}$, Yenen MC, Başer İ. Comparison of four malignancy risk indices in the detection of malignant ovarian masses. J gynecologic oncology. 2011 Sep 1;22(3):177-82.

17. Park JW, Park JH, Song ES, Lee BI, Lee JH, Kim $\mathrm{KW}$, et al. Four risk of malignancy indices in evaluation of pelvic masses. Korean J Obst Gynecol. 2012 Sep 1;55(9):636-43.

Cite this article as: Singhal S, Rajoria L, Mital P, Batar A, Ainani R, Agarwal M, et al. Risk of malignancy index 4 in preoperative evaluation of patients with ovarian tumours. Int J Reprod Contracept Obstet Gynecol 2018;7:2464-71. 